Article

\title{
Healthy Lifestyles of Italian and Latvian university students, according to demographics, nationality, and study specialty with special reference to sport studies.
}

\author{
Vecenane H. ${ }^{1}$, Usca S. ${ }^{2}$, Cicchella A. ${ }^{3}$ \\ ${ }^{1}$ Faculty of Pedagogy and Social work, Liepaja University, Latvia \\ ${ }^{2}$ Faculty of Education, Languages and Design, Rezekne Academy of Technologies, Latvia \\ ${ }^{3}$ Department of Quality of Life Studies, University of Bologna, Italy.
}

\begin{abstract}
This study compares lifestyle behaviour of Italian and Latvian university students, with special reference to sport students, to assess if there are differences for gender, age, university or studies specialties. An online questionnaire investigating healthy lifestyle habits and 8 wellness dimensions has been compiled by 155 (43,9\% females) respondents from Italy (all having Italian nationality) and 132 from Latvia (76,5\% females, all having Latvian nationality) The responses were collected between April and December 2020. Presence of smokers in our sample is negligible. The questionnaire showed a good internal consistency (Cronbach $\alpha=.933$ ). On the total group, statistically significant differences in all the dimensions regarding age, gender, study specialty and university. Physical activity was associated with healthier lifestyle choices. Geographical differences were found (eating and sleeping behaviours, alcohol awareness) as well as socio-economic differences. Female students showed being more stressed than males. Occupational wellness increased by age. Sport students showed more health awareness. Many of the differences found between males and females in the total group disappeared when comparing only sport students of the two universities.
\end{abstract}

Keywords: Healthy lifestyle; sport studies; physical wellness, intellectual wellness, emotional wellness; social wellness; spiritual wellness, environmental wellness, occupational wellness; financial wellness

\section{Introduction.}

Quality of life of University students is a major concern for public health, and has been studied extensively, referring to mental health [1,2], physical activity and nutrition $[2,3]$, health related lifestyles [3,4] such as alcohol, drug abuse and sleeping habits. Selfperception of healthy lifestyle determinants of university students have been studied less $[5,6,7]$. The results of these studies are linked to the specificity of the social environment, and the interpretation of the results is also influenced by the cultural context, for example, religion [8]. Family conditions and social participation (friendships) had been associated to healthy lifestyle choices [9]. There is an evidence that lifestyles acquired during youth years, continue to persist even in adulthood [10], thus making it important to know how these lifestyles develop. The university life brings major changes in lifestyles, including reduced parental control and increased individual autonomy. Stress and freedom are sometimes associated with alcohol and tobacco consumption, less physical activity, and low consumption of fruit and vegetables $[10,11,12]$. Socio - economic factors have been hypothesized to be the determinants of certain lifestyle choices [13], and it is also known that geographical location influences the mood and thus life habits, sleeping and eating [14]. Gender also influences lifestyle perceptions, as shown in a Swedish study of university students. Males reported to be less stressed, and their health, fitness and mental health level was rated higher than females [15]. The same study shows how self-rated health can be predicted by gender and ethnicity [15]. Another study of Spanish university students 
[17] found similar results for gender, showing that a significantly greater proportion of men perceived their health as excellent when compared to women, and that men were more involved in sports, both actively than passively. The cohort analyzed in this study, however, does not include sport students. A large multi-centric study, performed in 6 countries (health professions), shows a better health perception in females but also a higher stress perception. In this study, the female's self-rated health perception was slightly higher than for males: they ate breakfast more frequently, reported higher levels of physical activity and spent more time studying [18]. The female students of a Greek university showed higher scores for healthy eating, had a lower rate of overweight/obesity and a lower rate of alcohol consumption [19]. Better behaviors in female students with regards to alcohol consumption was observed also in a cohort of general students (nursing) from Sweden, which also tended to be more stressed than males, while males were found to be more at risk of overweight/obesity and less interested in nutrition advice [20]. The field of study seems to be another factor which influences the lifestyle. A study performed in health, education and other disciplines in Spain, reveals that students enrolled in education (34\% of the sample) and other disciplines show a prevalence of tobacco consumption compared to health students (41 vs $22 \%$ ). This high percentage of smokers (22\%) in health professions, found in this study, is quite surprising and has not be observed in other countries [21], where health students were researched. Health students also showed higher consideration for physical activity [20].

A study investigating a sample like ours for geographical distribution, shows that sport students seem more aware of their health status [22] and they take care of their health. Polish (northern) students consume more vegetables and liquids, while Spanish consume more seafood, more dairy products, less alcohol and less tobacco [22]. Nutritional habits have found to be associated with sleeping [23], and being a poor sleeper results in an increased consumption of calories [23].

Interestingly, it seems that poor sleep of medical students was observed in different countries: $40.60 \%$ of Iranian students reported poor quality of sleep [24] while $69 \%$ of Lithuanian medical students reported good to excellent nocturnal sleep [25]; 70\% of Hong Kong students of medicine reported sleep deprivation [26], 47.1\% of medical students in India reported refreshing sleep [27], and 31.5\% of medical students suffered from sleep deprivation according to a study conducted in Nepal [28]. Physical activity of university students has been largely researched in scientific literature [3,5,6,17,22,23,29] also comparing different geographical provenience [22]. Significant associations were established between physical inactivity and the time exposed to screens, studying time, feeling low,smoking, and anxiety [30,31]. Physical activity patterns are also influenced by the socio-cultural context, for example, in a study performed in the United Arab Emirates showed a marked difference in male and female students about physical activity [32]. Environmental and meteorological conditions also influence the patterns of physical activity, for example, a study in Norway shows a relationship of the level of physical activity and depressive symptoms in university students [33]. Afro-American students have a poor perception of exercising for health and mental health benefits and of having good nutritional habits for healthy eating [34]. In a large study performed with North American students (with a low percent of Afro-American students among respondents), males reported higher intake of fruits and vegetables, higher physical activity levels, lower stress levels, and poorer quality of sleep than females. In this study, gender was found to be related to general lifestyle behaviors, which strengthen the results reported in the previous literature [35]. There are very few studies comparing a Northern country with a Southern country, different for geographical/environmental and socio-economic characteristics [22].

This study aims at investigating the lifestyle behaviours of a university students, to assess a) if there are differences in lifestyles behaviour according to the age and gender; b) if there are differences between students enrolled in different study courses, c) if there are differences according to geographical location of the students (e.g., North and South Europe). A further investigation was conducted with sport students. We hypothesized 
that there were less differences between the genders in lifestyle behaviours in sport students compared to non-sport group, thus a comparison of Italian and Latvian sport student subgroupswas also performed.

\section{Methods.}

The students participating in this research come from two different universities: one belonging to south Europe (Bologna), the other to north Europe (Liepaja). Bologna city

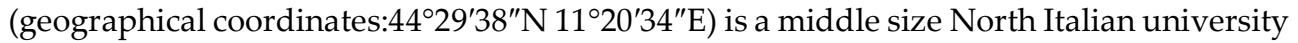
town of 395.000 habitants with a student population of 70.000. Liepaja is a middle size university town of Latvia (geographical coordinates: $56^{\circ} 30^{\prime} 42^{\prime \prime} \mathrm{N} 21^{\circ} 00^{\prime} 50^{\prime \prime} \mathrm{E}$ ) of $80.000 \mathrm{hab}-$ itants with a student population of 1400 . Environmental mean temperature $\left(8,2^{\circ}\right.$ Celsius in Latvia vs 14,3C in Italy) and economic conditions (pro-capita income $29.901 \$$ in Latvia - vs 39.637\$ in Italy) are quite different between the two countries.

Recruiting of respondents was done by word-of-mouth, email messages, andon social networks, and during lessons. In Latvia, due to the smaller numbers, the recruiting was done directly during the lessons. In addition, a total of 1600 emails were sent to themail list of Bologna University, Bologna and Rimini Campus, sport studies. All the students of Bologna were Italian and all the students from Liepaja were Latvian. All students were natives of their country. The students compiled an online questionnaire [36], previously validated [37]. The questionnaire was anonymous, and both Ethical Committees of Liepaja and Bologna Universities approved the study protocol. Informed consent was requested of the participants prior to the survey. The questionnaire aimed at investigating the Overall Healthy Lifestyle and 8 wellness dimensions: Physical, Intellectual, Emotional, Social, Spiritual, Environmental, Occupational, Financial. Each dimension is assessed by 10 items. Each item can be answered in a 3-grade scale: Almost always $=4$ points; Sometimes/occasionally $=2$ points; Very seldom $=1$ points. Answers were collected between April and December 2020. This period is in the beginning of Covid19 pandemic, and this fact could have impacted the responses. However, we do not have any previous data to assess this point. The recruiting in Latvia were made in classes taught in person, because at that time Latvia was at the beginning of pandemic and there were not yet restrictions on classroom teaching. Thus, the results can be useful for a further study to compare with post-covid19 conditions.

Statistical analysis was performed with SPSS v.25. At first, Cronbach's alpha test was performed to determine the internal consistency of the survey which gave an $\alpha=.933$. The answers were assessed for normality with the Kolmogorov-Smirnov $(p<.05)$, which suggested using the nonparametric tests. Then, Kruskal-Wallis and Mann-Whitney tests were performed. The first comparison was performed between universities (country), gender, age and study programmes in the whole sample of students, then a comparison between Italian and Latvian students was performed on the same variables but 0 for sport students.

\section{Results.}

In the whole sample, there were 155 (43,9\% females) respondents from Italy (all having Italian nationality) and 132 from Latvia (76,5\% females, all having Latvian nationality). The female percent was higher for Latvian students. This difference can be explained by the high percentage of females in Latvia population, compared to Italy (84,8 males/100 females in Latvia vs 94,6 in Italy), and with a presence of primary school teachers in Liepaja sample. Age of the students is reported in Table 1. The students belong to different study programmes (Table 2$)$. Smokers' \% in the sample was negligible $(12,9 \%$, for Italians and $12,9 \%$ for Latvian). 
Table 1. Student demographics, according to country.

\begin{tabular}{ccccccc}
\hline \multirow{2}{*}{ Age (years) } & \multicolumn{2}{c}{ All respondents } & \multicolumn{2}{c}{ Respondents from Italy } & \multicolumn{2}{c}{ Respondents from Latvia } \\
\cline { 2 - 7 } & Cases & Percent & Cases & Percent & Cases & Percent \\
\hline $18-22$ & 130 & 45.3 & 93 & 60 & 37 & 28 \\
$23-28$ & 92 & 32.1 & 55 & 35.5 & 37 & 28 \\
$29-34$ & 27 & 9.4 & 3 & 1.9 & 24 & 18.2 \\
$35+$ & 38 & 13.2 & 4 & 2.6 & 34 & 25.8 \\
\hline
\end{tabular}

Distribution for age shows that a significant \% of the sample is over 30 . This is due to the students enrolled in the teacher education programmes. One respondent $(0.4 \%)$ did not indicate his/her age. Distribution for age shows that a significant \% of the Latvian sample is over 30. This is due to the subjects enrolled in the schoolteacher's study course. This is due to the students enrolled in the teacher education programmes.

Table 2. Distribution by study course.

\begin{tabular}{ccc}
\hline \multirow{2}{*}{ Age (years) } & \multicolumn{2}{c}{ All respondents } \\
\cline { 2 - 3 } & Cases & Percent \\
\hline basic education teacher & 14 & 4.9 \\
preschool teacher & 52 & 18.1 \\
music teacher & 5 & 1.7 \\
sport field & 201 & 70 \\
other & 15 & 5.1 \\
\hline
\end{tabular}

Using the Kruskal-Wallis and Mann-Whitney test, it was determined whether there are statistically significant differences in the evaluations according to the respondents profile. Results are summarized in Table 3.

Table 3. Statistically significant differences.

\begin{tabular}{lccccc}
\hline \multirow{2}{*}{ Wellness Dimensions } & \multirow{2}{*}{$\alpha$} & \multicolumn{4}{c}{ Statistically significant differences (p) } \\
\cline { 3 - 6 } & & University & Gender & Discipline & Age \\
\hline Overall Healthy Lifestyle & .819 & .000 & .027 & .000 & .000 \\
Physical Wellness & .816 & .000 & .003 & .000 & 000 \\
Intellectual Wellness & .817 & .001 & - & - & .002 \\
Emotional Wellness & .818 & .000 & .021 & .000 & .000 \\
Social Wellness & .818 & .002 & - & .000 & .010 \\
Spiritual Wellness & .815 & .002 & .046 & .006 & - \\
Environment Wellness & .817 & .000 & - & .000 & .000 \\
Occupational Wellness & .832 & - & .036 & - & .000 \\
Financial Wellness & .833 & .001 & - & - & - \\
\hline
\end{tabular}


Several statistically significant differences were found between respondent's speciality of study. Statistically most significant differences $(\mathrm{p}=.000)$ were found in the evaluation of the Overall Healthy Lifestyle: the highest score was obtained in Sport students (Mean 80.51) and other programs (Mean 82,73); the lowest evaluation score was observed in Basic education teachers' programs (Mean 70,36) and Music teachers' programs (Mean 70,60). This result is not surprising, being as sport students are more involved in health studies. The same result was ob-served $(\mathrm{p}=.000)$ in the scores of Physical Wellness: the highest evaluation was given in Sport field (Mean 26.96) and other programs (Mean 27.13); the lowest evaluation was observed in the Basic education teachers and Music programs (Mean 22.29, and 20.20). In Emotional Wellness ( $p=.000)$ the highest score was observed in Sport field (Mean 27.11) and other's programs (Mean 32.00); the lowest in the Basic education and Preschool teachers (Mean 23.54 and 4.96). Even in this dimension, sport appears to have a regulating effect on emotional wellbeing. In Social Wellness (0.000), the highest grade score was obtained by Sport students (Mean 27.75) and other programs (Mean 35.00); the lowest scores were observed in the Basic education teachers' programs (Mean 25.76). In Environment Wellness ( $p=.000)$, the highest score was obtained by Sport students (Mean 26.82) and other programs (Mean 32.46); the lowest in Basic education and Preschool teachers' programs (Mean 23.92 and 23.96). Also, the Spiritual Wellness show a very signifi-cant differences between groups ( $\mathrm{p}=.006)$ : respondents who study in other programs gave it the highest evaluation (Mean 33.39), followed by respondents which study in Music teachers' programs (Mean 31.40), and by respondents who study in Basic education teachers' programs gave the lowest evaluation (Mean 25.31).

Several statistically significant differences were found according to the respondent's age (see Mean Rank in Graph 1)

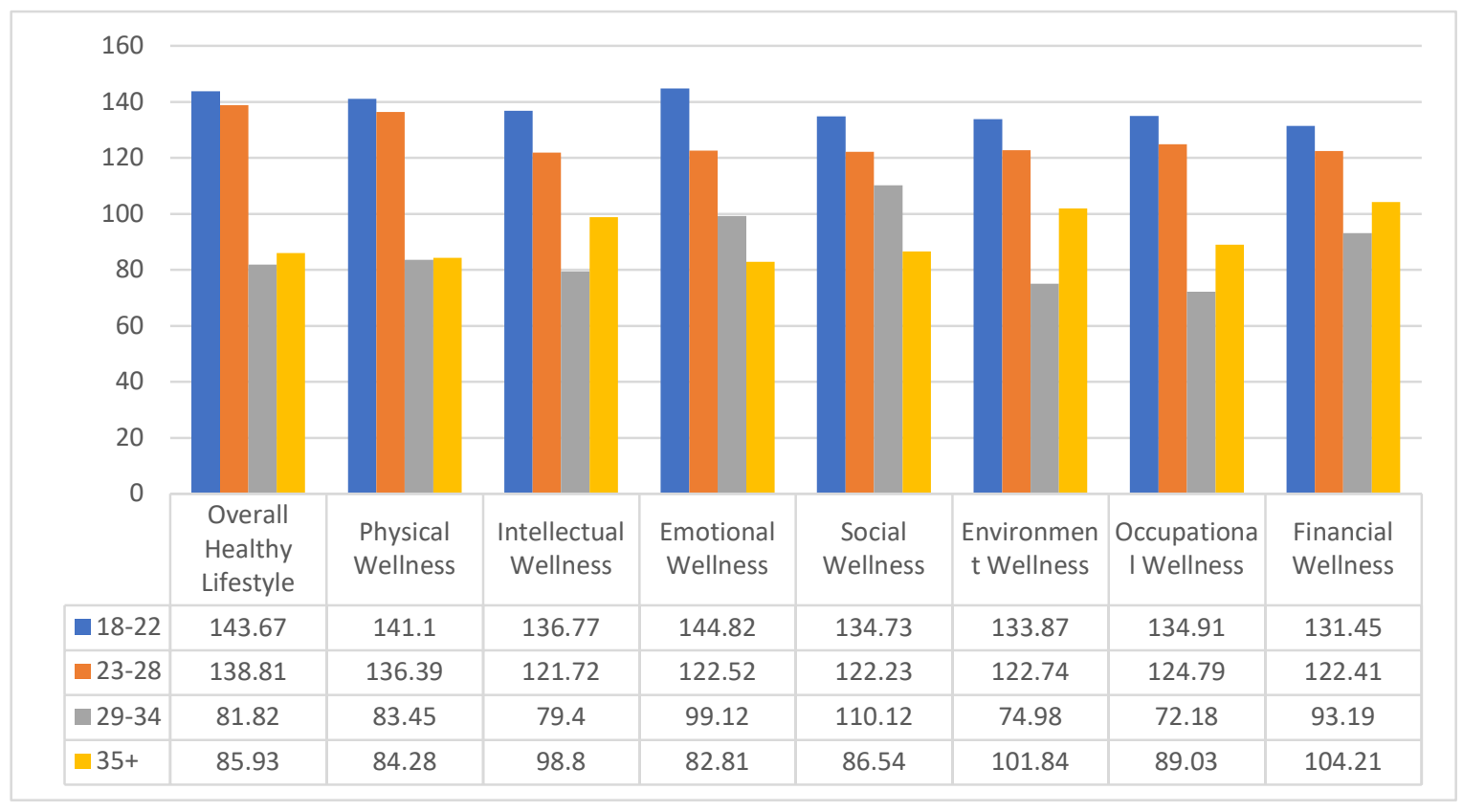

Graph 1. Ranks of the different wellness dimensions by age.

All dimensions decline with age with some exception for the +35 group. The older age is explained with the presence of a group of school teachers following an education curriculum. Intellectual, Environmental, Occupational and Financial wellness, increase in the +35 group. This result can be explained by the fact that the older subjects have a job and can afford better lifes conditions. 
Results for gender are reported as Mean Rank in Graph 2. Males perceived to be better in all considered dimensions. This result confirms the findings of other studies, which indicate a need for the improvement of the condition of female students in the university $[6,8,12]$.

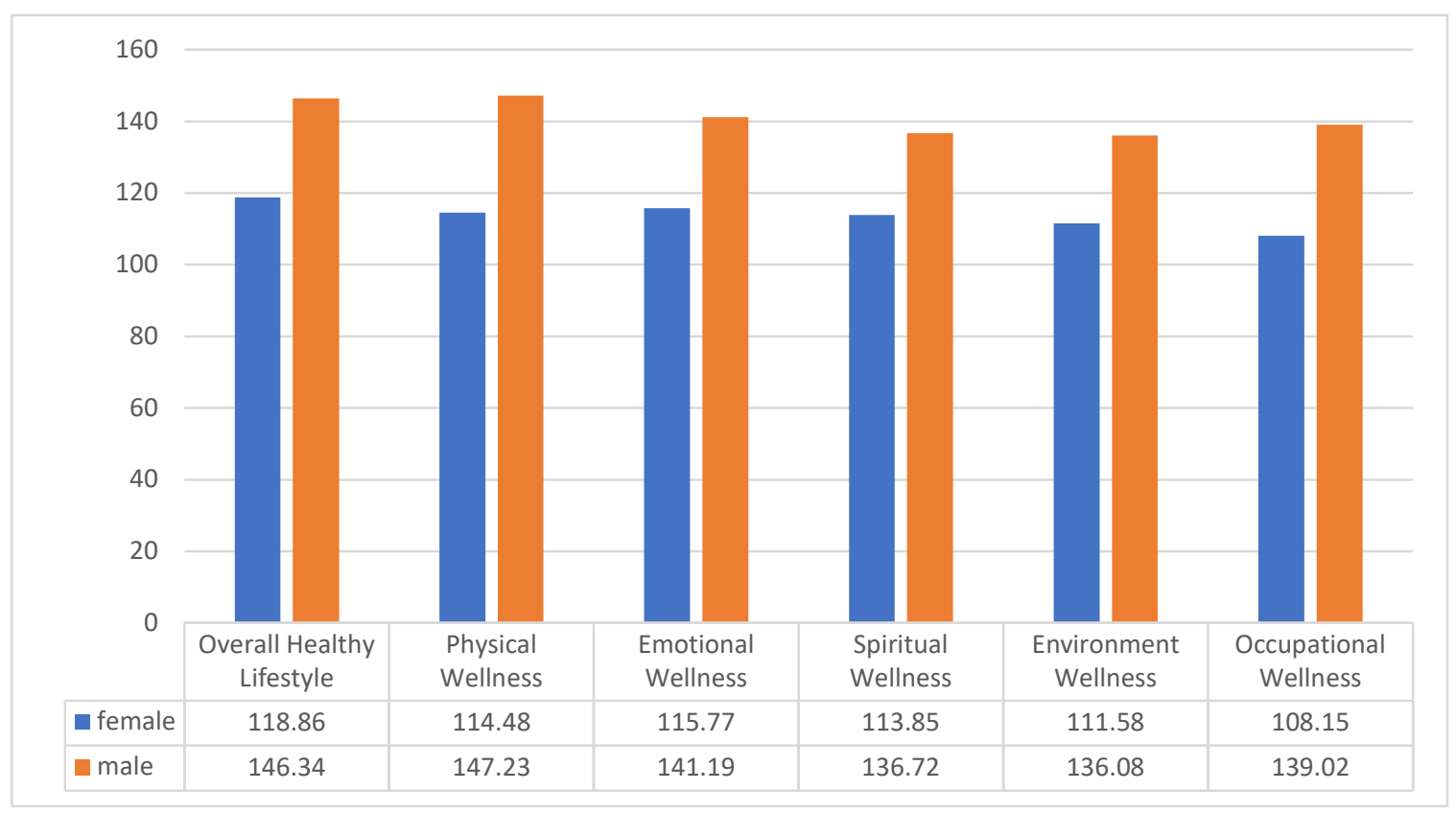

Graph 2. Dimensions Rank by gender.

Bologna students perceived themselves better in all the considered dimensions of wellness in comparison to Latvian students (Graph 3). These results probably reflect the different socio-economic and the geographic/environment, and is accord with the results a previous study comparing a Northern and a Southern Europe cohort of students [22].

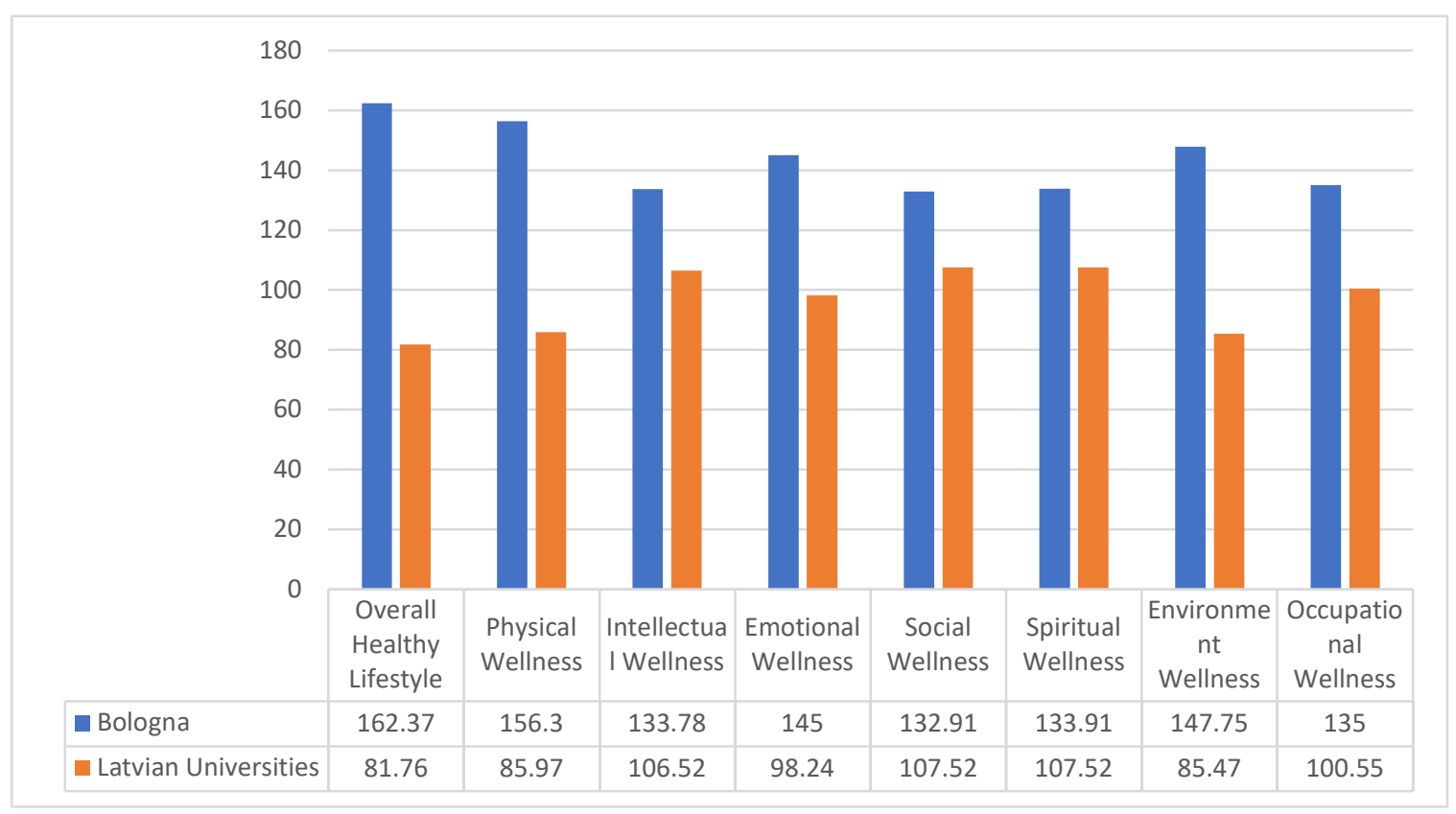

Graph 3. Bologna and Latvian students rank. 
Comparison of Latvian and Italian Sport students.

The respondents belonging to sport studies were 140 (in a total population of 1000) from Bologna and 61 from Liepaja (on a total population of 60). Age distribution is mostly in the range 18-28 years old. Liepaja students are of older age, because of the presence of a continuum education courses for elementary school teachers in the sample. Age distribution in sport students is reported in Table 4. Age distributions for sport students are like the total sample distribution. Italian students are younger than Latvian.

Table 4. Age Distribution for Sport Students (\%).

\begin{tabular}{cccc}
\hline Age (years) & Total Sport \% & Italy $\%$ & Latvia $\%$ \\
\hline $18-22$ & 46.8 & 56.4 & 24.6 \\
$23-28$ & 39.3 & 38.6 & 41.0 \\
$29-34$ & 7.5 & 2.1 & 19.7 \\
$35+$ & 6.4 & 2.9 & 14.7 \\
\hline
\end{tabular}

Cronbach's alpha test was performed to determine the internal consistency of the survey which gave an $\alpha=.926$. In Table 5, significant differences by country/university and are reported for sport students and Cronbach's alpha for each dimension.

Table 5. Cronbach's alpha coefficient and statistically significant differences (only Sport students). Physical Wellness and Financial Wellnees show a low consistency, thus was not considered in the analysis.

\begin{tabular}{lccc}
\hline & & \multicolumn{2}{c}{ Statistically significant differences (p) } \\
\cline { 3 - 4 } Wellness Dimensions & $\alpha$ & University & Age \\
\hline Overall Healthy Lifestyle & .753 & .000 & - \\
Physical Wellness & .595 & .000 & 0.10 \\
Intellectual Wellness & .755 & .001 & .050 \\
Emotional Wellness & .756 & .002 & - \\
Social Wellness & .732 & .016 & - \\
Spiritual Wellness & .816 & .024 & .002 \\
Environment Wellness & .764 & .000 & .014 \\
Occupational Wellness & .851 & - & - \\
Financial Wellness & .545 & .022 & - \\
\hline
\end{tabular}

Several statistically significant differences were found according to the respondent's University and fewer differences for age.

Differences in the Overall Lifestyle are shown in Table 6. 
Table 6. Differences by country in sport students in Overall Healthy Lifestyles. Mean scores.

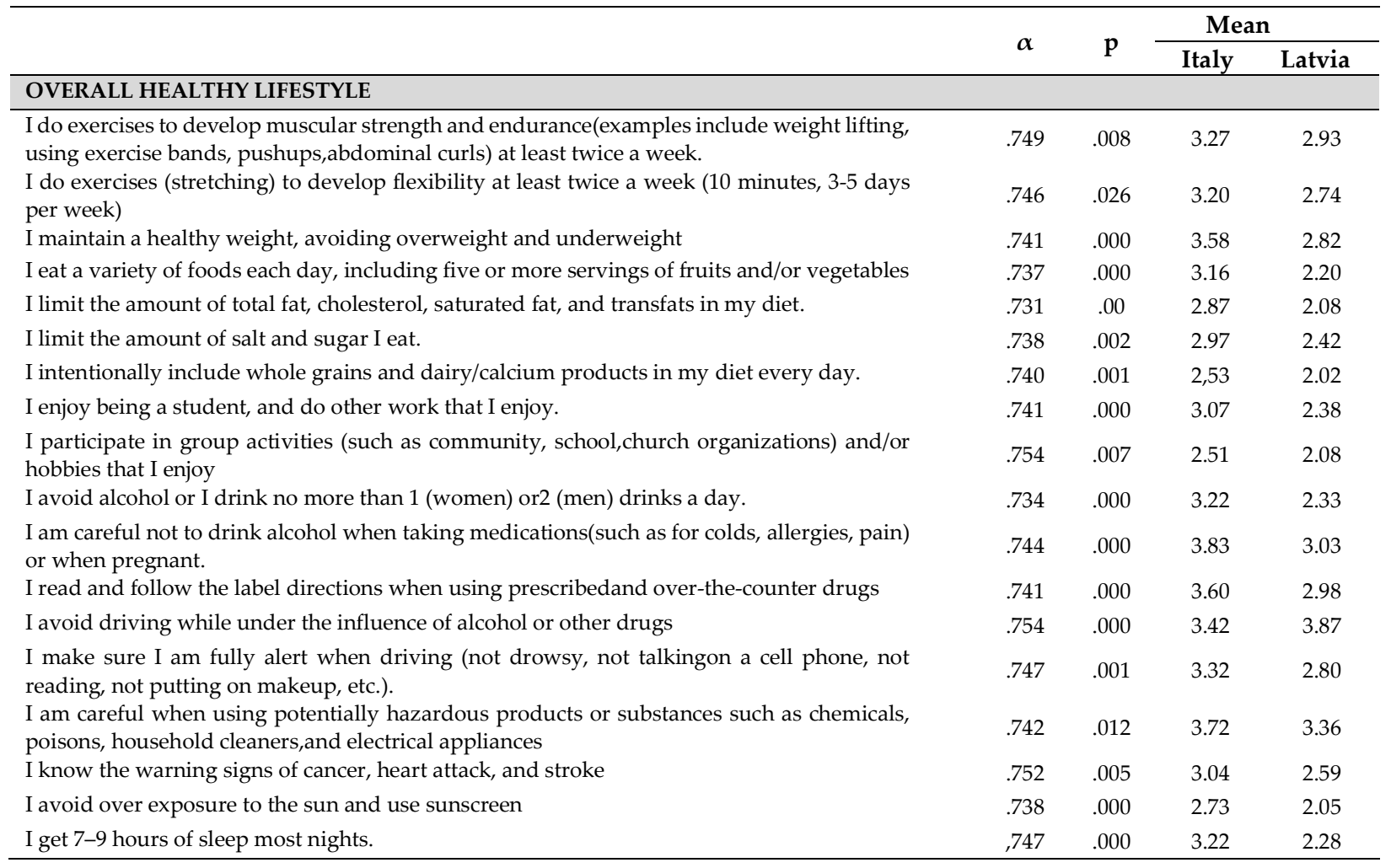

Overall, Italian's sports students are more aware of their food consumption. Alcohol and drugs awareness is higher in Latvian students. Higher consumption of fruit in Italian students are probably linked to geographical reasons as well awareness of sun exposure [ 38]. However, differences that can be explained with the geographical location has been evidenced also in other studies comparing European northern and southern countries [22]. Again, it is interesting to observe that eating habits reflect the geographical location, as well as habits about sun exposure. Italians eat more fruits and whole grain. Also, they are more aware of the risk of saturated fat and alcohol eating and drinking and of sleep and healthy weight to maintain health. This result is in accord with previous findings about the association between sleep and moderate to intense physical activity in university students [39]. Diet is also a major concern for Italian students, and it is known that diet is related to stress [40], sleep [41] and overall mental health [42].

In table 7 statistical significant differences are shown for Intellectual, Emotional, Social, Spiritual

, Environmental and Occupation Wellness dimensions. 
Table 7. Differences between Latvian and Italian Sport students. Mean scores.

\begin{tabular}{|c|c|c|c|c|}
\hline \multicolumn{5}{|l|}{ INTELLECTUAL WELLNESS } \\
\hline \multirow{2}{*}{ statement } & \multirow{2}{*}{$\alpha$} & \multirow{2}{*}{$\mathrm{p}$} & \multicolumn{2}{|c|}{ Mean } \\
\hline & & & Italy & Latvia \\
\hline I seek opportunities to learn new things & .728 & .050 & 3.38 & 3.08 \\
\hline I try to keep abreast of current affairs-local, national, and international & .724 & .041 & 2.58 & 2.25 \\
\hline I enjoy attending special lectures, plays, musical performances, museums, galleries, and/or libraries & 7.53 & .000 & 2.58 & 3.20 \\
\hline I enjoy watching educational programs on TV & 7.24 & .003 & 2.39 & 1.93 \\
\hline I enjoy creative and stimulating mental activities/games. & .727 & .000 & 2.96 & 2.28 \\
\hline A continuing education program is/will be important to me in my career & .748 & .002 & 3.36 & 3.75 \\
\hline I am able to analyze, synthesize, and see more than one side of an issue. & .744 & .000 & 3.45 & 2.66 \\
\hline I enjoy engaging in intellectual discussions & .735 & .000 & 3.03 & 2.08 \\
\hline \multicolumn{5}{|l|}{ EMOTIONAL WELLNESS } \\
\hline \multirow{2}{*}{ statement } & \multirow{2}{*}{$\alpha$} & \multirow{2}{*}{$\mathrm{p}$} & \multicolumn{2}{|c|}{ Mean } \\
\hline & & & Italy & Latvia \\
\hline I see challenges and change as opportunities for growth & .729 & .000 & 3.51 & 2.92 \\
\hline I am able to laugh at life and myself & .725 & .001 & 3.26 & 2.74 \\
\hline I relax and enjoy life without the use of alcohol or drugs & .747 & .005 & 3.43 & 2.97 \\
\hline \multicolumn{5}{|l|}{ SOCIAL WELLNESS } \\
\hline \multirow{2}{*}{ statement } & \multirow{2}{*}{$\alpha$} & \multirow{2}{*}{$\mathrm{p}$} & \multicolumn{2}{|c|}{ Mean } \\
\hline & & & Italy & Latvia \\
\hline I contribute time $+\mathrm{BJ} 1$ :BS1and/or money to social and community projects & .745 & .000 & 1.88 & 1.38 \\
\hline I obey the laws and rules of our society & .735 & .000 & 3.36 & 2.77 \\
\hline I am a compassionate person and try to help others when I can & .700 & .044 & 3.48 & 3.18 \\
\hline \multicolumn{5}{|l|}{ SPIRITUAL WELLNESS } \\
\hline \multirow{2}{*}{ statement } & \multirow{2}{*}{$\alpha$} & \multirow{2}{*}{$\mathrm{p}$} & \multicolumn{2}{|c|}{ Mean } \\
\hline & & & Italy & Latvia \\
\hline There is a direct relationship between my personal values and my daily actions & .794 & .000 & 3.29 & 2.56 \\
\hline Prayer, meditation, and/or quiet personal reflection is/are important in my life & .801 & .030 & 2.48 & 2.08 \\
\hline I am able to speak comfortably about my personal values and beliefs & .796 & .001 & 3.09 & 2.49 \\
\hline I am tolerant of and try to learn about others' beliefs and values & .807 & .000 & 3.26 & 2.51 \\
\hline \multicolumn{5}{|l|}{ ENVIRONMENT WELLNESS } \\
\hline \multirow{2}{*}{ statement } & \multirow{2}{*}{$\alpha$} & \multirow{2}{*}{$\mathrm{p}$} & \multicolumn{2}{|c|}{ Mean } \\
\hline & & & Italy & Latvia \\
\hline I consciously conserve energy (electricity, heat, light, water, etc.) in my place of residenceand work & .733 & .000 & 3.07 & 2.26 \\
\hline I practice recycling (glass, paper, plastic, etc.). & .744 & .000 & 3.74 & 1.85 \\
\hline I am committed to cleaning up the environment (air, soil, water, etc.). & 7.46 & .006 & 3.07 & 2.59 \\
\hline I limit the use of fertilizers and chemicals when managing my yard/lawn/outdoor living space & .728 & .000 & 3.22 & 2.38 \\
\hline I limit my use of aerosol sprays & .738 & .000 & 3.22 & 2.08 \\
\hline I do not litter & .774 & .002 & 3.00 & 3.49 \\
\hline I volunteer my time for environmental conservation projects & .746 & .000 & 1.68 & 1.20 \\
\hline
\end{tabular}




\begin{tabular}{|c|c|c|c|c|}
\hline I purchase recycled items when possible, even if they cost more & .722 & .000 & 2.44 & 1.38 \\
\hline \multicolumn{5}{|l|}{ OCCUPATIONAL WELLNESS } \\
\hline \multirow{2}{*}{ statement } & \multirow{2}{*}{$\alpha$} & \multirow{2}{*}{$\mathrm{p}$} & \multicolumn{2}{|c|}{ Mean } \\
\hline & & & Italy & Latvia \\
\hline I look forward to working in my career area & .861 & .000 & 3.43 & 2.59 \\
\hline I am happy with the balance between my work/career choice time commitment and leisure time. & .839 & .002 & 2.94 & 2.43 \\
\hline My job/career choice contributes positively to my overall well-being. & .836 & .004 & 3.20 & 3.61 \\
\hline
\end{tabular}

Italian students show higher rankings in social wellness. In a comparative study on mental health of German and Chinese students, more regular social rhythm and physical activity was associated with better mental health [43].

. We didn't find significant differences between males and females sport students.

. A masculinization of sport studies has been observed before [44,45] and attributed to social reasons, such as a less female culture in sport studies [44]. Also, cultural conduits in the construction and transmission of male gender orientations and practices in the profession has been observed in PE teachers [46,47]. This result is different from previous findings in Swedish university students (general curriculum), which found the females more stressed than males [15], a similar result was found in female medical students [48].

\section{Conclusions.}

Overall, it appears there are not substantial (significant) differences between males and females, between universities, between ages, and between degrees in all the dimensions of healthy lifestyles. Environmental factors, as well as socio-demographic factors can explain the differences between Italian and Latvian students. Geographical latitude seems to influence the eating habits. Despite the politics to improve the females' conditions in the society, not much has been done in the university to empower female students, which still show worse scores than males in many positions. The overall health perception improves significantly with age, and this can be explained by better economic conditions. From the answers, it arises that sport students are more aware of their health, in comparison to the other groups. In our sample, the presence of smokers is negligible, while alcohol seems to be an important health concern in all samples, and more in sport students. Female/male differences are present in the sport students, albeit these differences are few if compared to the gender's differences found in the total sample. We can hypothesize this to be an effect of sport practice, which has a 'masculinization' effect, but this hypothesis must be researched to draw firm conclusions. A limit of our study is the limited number of students tested in sport, especially in the Latvian sample, albeit they represent a large percent of the respective populations. Also, we did not consider any physiologic parameters, for example heart rate variability at rest who has been shown to relate to the lifestyles or body weight, which could have been useful to better interpret some associations we found. These data can be useful for better understanding of the influence of sport studies on healthy lifestyles and design intervention program to improve healthy lifestyle targeting university students involved in different disciplines, to reduce some disparities between males and female' students, and for designing double degree university courses between Latvia and Italy. Further, the study can be useful for a post-pandemic comparison.

\section{References.}

[1]. Auerbach, R. P.; Alonso, J.; Axinn, W. G.; Cuijpers, P.; Ebert, D. D.; Green, J. G.; Hwang, I.; Kessler, R. C.; Liu, H.; Mortier, P. et al. (2016). Mental disorders among college students in the World Health Organization World Mental Health Surveys. Psychological medicine 2016, 14, 2955-2970. https://doi.org/10.1017/S0033291716001665. 
[2]. Sheldon, E.; Simmonds-Buckley, M.; Bone, C.; Mascarenhas, T.; Chan, N.; Wincott, M.; Gleeson, H.; Sow, K.; Hind, D.; Barkham, M. Prevalence, and risk factors for mental health problems in university undergraduate students: A systematic review with meta-analysis. J Affect Disord. 2021, 287,282-292. doi: 10.1016/j.jad.2021.03.054.

[3]. Hervás, G.; Ruiz-Litago, F.; Irazusta, J.; Fernández-Atutxa, A.; Fraile-Bermúdez, A.B.; Zarrazquin, I. Physical Activity, Physical Fitness, Body Composition, and Nutrition Are Associated with Bone Status in University Students. Nutrients. 2018,10,61. doi: 10.3390/nu10010061.

[4]. Plotnikoff, R.C.; Costigan, S.A.; Kennedy, S.G.; Robards, S.L.; Germov, J.; Wild, C. Efficacy of interventions targeting alcohol, drug and smoking behaviors in university and college students: A review of randomized controlled trials. J Am Coll Health. 2019, 67, 68-84. doi: 10.1080/07448481.2018.1462821.

[5]. Yahia, N.; Wang, D.; Rapley, M.; Dey, R. Assessment of weight status, dietary habits and beliefs, physical activity, and nutritional knowledge among university students. Perspect Public Health. 2016, 136, 231-44. doi: $10.1177 / 1757913915609945$.

[6]. Aceijas, C.; Waldhäusl, S.; Lambert, N.; Cassar, S.; Bello-Corassa, R. Determinants of health-related lifestyles among university students. Perspect Public Health. 2017, 137, 227-236. doi: 10.1177/1757913916666875.

[7]. Reshetnikov, A.V.; Prisyajnaya, N.V.; Reshetnikov, V.A.; Efimov, I.A. [The Features of Healthy Life-Style Perception by Students of Medical Universities]. Probl Sotsialnoi Gig Zdravookhranenniiai Istor Med. 2018, 26, 201-206. Russian. doi: 10.32687/0869-866X-2018-26-201-206.

[8]. Almutairi, K.M.; Alonazi, W.B.; Vinluan, J.M.; Almigbal, T.H.; Batais, M.A.; Alodhayani, A.A.; Alsadhan, N.; Tumala, R.B.; Moussa, M.; Aboshaiqah, A.E. et al. Health promoting lifestyle of university students in Saudi Arabia: a crosssectional assessment. BMC Public Health. 2018,18 :1093. doi: 10.1186/s12889-018-5999-z.

[9]. Çalışkan, C.; Arberk, K.; \& Üner, S. Healthy Lifestyle Behaviors of University Students. Prehospital and Disaster Medicine 2017, 32(S1), S213-S213. doi:10.1017/S1049023X17005544

[10]. Hultgren, B.A.; Turrisi, R.; Cleveland, M.J.; Mallett, K.A.; Reavy, R.; Larimer, M.E.; Geisner, I.M.; Hospital, M. Transitions in drinking behaviors across the college years: A latent transition analysis. Addict. Behav. 2019,92, 108-114. [11]. Dodd, L.J.; Al-Nakeeb, Y.; Nevill, A.M.; Forshaw, M.J. Lifestyle risk factors of students: A cluster analytical approach. Prev. Med. 2010, 51, 73-77.

[12]. Assaf, I.; Brieteh, F.; Tfaily, M.; El-Baida, M.; Kadry, S.; Balusamy, B. Students university healthy lifestyle practice: Quantitative analysis. Heal. Inf. Sci. Syst. 2019, 7, 7.

[13]. Campos-Matos, I.; Russo, G.; Perelman, J. Connecting the dots on health inequalities-a systematic review on the social determinants of health in Portugal. Int. J. Equity Heal. 2016, 15, 26.

[14]. Wirz-Justice A. Seasonality in affective disorders. Gen Comp Endocrinol. 2018, 258, 244-249. doi: 10.1016/j.ygcen.2017.07.010.

[15]. Schmidt, M. Predictors of self-rated health and lifestyle behaviours in Swedish university students. Glob J Health Sci. 2012, 4, 1-14. doi: 10.5539/gjhs.v4n4p1.

[16]. Sáez, I.; Solabarrieta, J.; Rubio, I. Physical Self-Concept, Gender, and Physical Condition of Bizkaia University Students. Int J Environ Res Public Health. 2020, 17, 5152. doi: 10.3390/ijerph17145152.

[17]. Andrés-Villas, M.; Díaz-Milanés, D.; Remesal-Cobreros, R.; Vélez-Toral, M.; Pérez-Moreno, P.J. Dimensions of Leisure and Perceived Health in Young University Students. Int J Environ Res Public Health. 2020, 17, 8750. doi: 10.3390/ijerph17238750.

[18]. Cena, H.; Porri, D.; De Giuseppe, R.; Kalmpourtzidou, A.; Salvatore, F.P.; El Ghoch, M.; Itani, L.; Kreidieh, D.; Brytek-Matera, A.; Pocol, C.B.; Arteta, D.S.; Utan, G.; Kolčić, I. How Healthy Are Health-Related Behaviors in University Students: The HOLISTIC Study. Nutrients 2021, 13, 675. https://doi.org/10.3390/nu13020675 
[19]. Tirodimos, I., Georgouvia, I., Savvala, T.N., Karanika, E. \& Noukari, D. Healthy lifestyle habits among Greek university students: differences by sex and faculty of study. EMHJ - Eastern Mediterranean Health Journal 2009 , 15 , 722-728.

[20]. Bothmer, M. I.K.V.; Fridlund, B. Gender differences in health habits and in motivation for a healthy lifestyle among Swedish university students. Nursing \& Health Sci. 2005, 7, 107-118. doi: doi.org/10.1111/j.14422018.2005.00227.x

[21]. Varela-Mato, V.; Cancela, J.M.; Ayan, C.; Martín, V.; Molina, A. Lifestyle and Health among Spanish University Students: Differences by Gender and Academic Discipline. Int. J. Environ. Res. Public Health 2012, 9, $2728-2741$. https://doi.org/10.3390/ijerph9082728

[22]. López-Sánchez, G.F.; Radzimiński, Ł.; Skalska, M.; Jastrzębska, J.; Smith, L.; Wakuluk, D.; Jastrzębski, Z. Body Composition, Physical Fitness, Physical Activity and Nutrition in Polish and Spanish Male Students of Sports Sciences: Differences and Correlations. Int J Environ Res Public Health. 2019, 16, 1148. doi: 10.3390/ijerph16071148.

[23]. Papaconstantinou, E.; Quick, V.; Vogel, E.; Coffey, S.; Miller, A.; Zitzelsberger, H. Exploring Relationships of Sleep Duration with Eating and Physical Activity Behaviors among Canadian University Students. Clocks Sleep 2020, 2, 194207.

[24]. Ghoreishi, A.; Aghajani, A.H. Sleep quality in Zanjan university medical students. Tehran Univ. Med. J. TUMS Publ. 2008, 66, 61-67.

[25]. Preišegolavičiūtè, E.; Leskauskas, D.; Adomaitienè, V. Associations of quality of sleep with lifestyle factors and profile of studies among Lithuanian students. Medicina 2010, 46, 482-489.

[26]. Huen, L.E.; Chan, T.-W.G.; Yu, W.-M.M.; Wing, Y.-K. Do medical students in Hong Kong have enough sleep? Sleep Biol. Rhythm. 2007, 5, 226-230.

[27]. Giri, P.; Baviskar, M.; Phalke, D. Study of Sleep Habits and Sleep Problems Among Medical Students of Pravara Institute of Medical Sciences Loni, Western Maharashtra, India. Ann. Med. Health Sci. Res. 2013, 3, 51-54.

[28]. Khadka, R.; Bista, S.; Baskota, S.; Poudel, L.; Gurung, M. Sleep Quality among College Students in Kathmandu Valley, Nepal. Nepal Med. J. 2019, 2, 1-4.

[29]. Carballo-Fazanes, A.; Rico-Díaz, J.; Barcala-Furelos, R.; Rey, E.; Rodríguez-Fernández, J.E.; Varela-Casal, C.; Abelairas-Gómez, C. Physical Activity Habits and Determinants, Sedentary Behaviour and Lifestyle in University Students. Int J Environ Res Public Health. 2020, 17, 3272. doi: 10.3390/ijerph17093272.

[30]. Zubiaur, M.; Zitouni, A.; Del Horno, S. Comparison of Sports Habits and Attitudes in University Students of Physical and Sports Education of Mostaganem (Algeria) and Physical Activity and Sport Sciences of León (Spain). Front Psychol. 2021, 11, 593322. doi: 10.3389/fpsyg.2020.593322.

[31]. Proença, M.; Furlanetto, K.C.; Morita, A.A.; Bisca, G.W.; Mantoani, L.C.; Pitta F. Profile and determinants of daily physical activity objectively assessed in university students. J Sports Med Phys Fitness. 2020,60, 1493-1501. doi: 10.23736/S0022-4707.20.11059-4.

[32]. Doyle, C.B.; Khan, A.; Burton, N.W. Recreational physical activity context and type preferences among male and female Emirati university students. Int Health. 2019,11507-512. doi: 10.1093/inthealth/ihz002.

[33]. Kleppang, A.L.; Hartz, I.; Thurston, M.; Hagquist, C. The association between physical activity and symptoms of depression in different contexts - a cross-sectional study of Norwegian adolescents. BMC Public Health. 2018, 18, 1368. doi: 10.1186/s12889-018-6257-0.

[34]. Barnett, M.;McFarland, A.; Miller, J.W.; Lowe, V.; Hatcher, S.S. Physical and Mental Health Experiences among African American College Students. Soc Work Public Health. 2019, 34, 145-157. doi: 10.1080/19371918.2019.1575308. 
[35]. Olfert, M.D.; Barr, M.L.; Charlier, C.C.; Greene, G.W.; Zhou, W.; Colby, S.E. Sex Differences in Lifestyle Behaviors among U.S. College Freshmen. Int J Environ Res Public Health. 2019, 16, 482. doi: 10.3390/ijerph16030482.

[36]. https:/docs.google.com/forms/d/e/1FAIpQLSdjF4CU7KIQZAI5j9C KrcCwFXh5wmw0GnNxtSI2EjFWhlbg/viewform. Last accessed: 26/04/2021.

[37]. Robbins, G.; Powers, D.; Burgess, S. A Wellness Way of Life, 9/e.5. 2011 McGraw Hill.

[38]. Driscoll, D.M. A perspective on weather-human response relationships, International Journal of Environmental Studies. 1990,36, 19-25. DOI: 10.1080/00207239008710580.

[39]. Memon, A.R.; Gupta, C.C.; Crowther, M.E.; Ferguson, S.A.; Tuckwell, G.A.; Vincent, G.E. Sleep, and physical activity in university students: A systematic review and meta-analysis. Sleep Med Rev. 2021, 20, 101482. doi: 10.1016/j.smrv.2021.101482.

[40]. Alfreeh, L.; Abulmeaty, M.M.A.; Abudawood, M.; Aljaser, F.; Shivappa, N.; Hebert J.R.; Almuammar, M.; AlSheikh, Y.; Aljuraiban, G.S. Association between the Inflammatory Potential of Diet and Stress among Female College Students. Nutrients. 2020 ,12, 2389. doi: 10.3390/nu12082389.

[41]. Da Silva, R.; Barbosa, M.L.; Rodrigues, B.; Da Silva, C.C.N.; Moura, A.A. Association between the Degree of Processing of Consumed Foods, and Sleep Quality in Adolescents. Nutrients 2020, 12, 462.

[42]. Muscaritoli, M. The Impact of Nutrients on Mental Health and Well-Being: Insights from the Literature. Front Nutr. 2021,, 656290. doi: 10.3389/fnut.2021.656290

[43]. Velten, J., Bieda, A., Scholten, S. et al. Lifestyle choices and mental health: a longitudinal survey with German and Chinese students. BMC Public Health 2018, 18, 632. https://doi.org/10.1186/s12889-018-5526-2

[44]. Payeras, P.S.; Prat, S.S.; Soler, A. V.; Hinojosa-Alcalde, I. Masculinization in Physical Activity and Sport Sciences Degree Programs. Apunts: Educació Física i Esports 2019, 135, 9-25.

[45]. Porto, B. Feminización y masculinización en los estudios de maestro y educación física en Galicia. Revista de Investigación en Educación 2009,, 6, 50-57.

[46]. David Brown, D.; Evans, J.Reproducing Gender? Intergenerational Links and the Male PE Teacher as a Cultural Conduit in Teaching Physical Education. Journal of Teaching in Physical Education 2004 23, 48-70. DOI: https://doi.org/10.1123/jtpe.23.1.48.

[47]. Serra, P.; Soler, S.; Prat, M.; Vizcarra, M.T.; Garay, B; Flintoff A. The (in)visibility of gender knowledge in the Physical Activity and Sport Science degree in Spain, Sport, Education and Society 2018, 23, 324-338. DOI: 10.1080/13573322.2016.1199016.

[48]. Burger, P.H.M.; Scholz, M. Gender as an underestimated factor in mental health of medical students. Ann Anat. 2018, 218, 1-6. doi: 10.1016/j.aanat.2018.02.005. 